\title{
The Adoption of Branchless Banking System as Part of Inclusive Financial Service: Extension of Technology Acceptance Model
}

\author{
Minyahil Assefa (Ass. Professor) ${ }^{1}$
}

\begin{abstract}
The advancement of information technology paves the way for the branchless banking system expansion. It introduced a new dimension to the banking system where services are delivered using agents, mobile, and internet outlets. This study examined the determinants of users' intention to adopt a branchless banking system (BBS) using agent, mobile, and internet outlets. Several banking studies of technology acceptance have examined the adoption of mobile, agent, and internet banking systems independently. In contrast, this study examined the agent, mobile, and internet banking system altogether. While the total effect of each outlet on behavioral intention is compared using PLS-SEM, the agent banking system is found to be the most trusted and useful branchless banking outlet followed by the mobile banking system. Previous studies argue that attitude has a significant effect on behavioral intention due to the overlook of important determinants and the effect of perceived usefulness (PU) and perceived ease of use (PEU) on attitude. However, the present study confirmed that whether more determinants of PU and PEU are loaded or omitted the effect of attitude on the behavioral intention to adopt a BBS is statistically significant. Furthermore, in contrast with the technology acceptance model (TAM) that suggested the direct effect of PEU and PU on attitude, the present study found that only PU has a significant direct effect on attitude. The present study has extended the original technology acceptance model by adding sociocultural factors, facilitating conditions (FC), and trust constructs. The result confirmed that FC (the existence of local agents and government guaranty on banking transaction) directly affects an individual's trust in BBS that leads to system adoption. The study also found that the effect of sociocultural factors on perceived usefulness is more substantial than its effect on perceived ease of use. Thus, the present study suggested that any elegant branchless banking system has no acceptance if it is not designed to align with the sociocultural values of the users, specifically to their religion.
\end{abstract}

Keywords: Technology acceptance model, Branch-less banking system, Sociocultural factors, Facilitating conditions, Trust

\section{Introduction}

Historically banking service has been provided only through the branch facilities. Today, technology has enabled customers to access banking services without entering into branches. Following the introduction of agent, mobile, and internet banking technologies, banks remotely

\footnotetext{
${ }^{1}$ minyahil04@gmail.com, Department of accounting and finance, Jigjiga University, Ethiopia.
} 
managed to interact with their customers. Moreover, this branchless banking platform makes banks to reach more unbanked people who are living in remote areas.

Traditionally the motives of financial policymakers were access to finance for the poor and unbanked rural people using informal financial institutions. However, informal financial institutions have experienced capacity limitations to address all financial needs of rural unbanked part of the community. Considering this fact, the recent development agenda of financial policymakers shifted into inclusive financial services[1]. The notion of inclusive financial service is the endowment of affordable, quality, and formal financial services to the unbanked people[2]

One of the main obstacles to financial inclusion is cost, both the cost incurred by the banks and the cost incurred by the customers. Banks have to invest large fixed costs in setting up and maintaining their branch network in the rural area. As a result, they opt to operate in urban areas. On the other side, rural area customers have to travel to these distant urban branches to get banking services by expending significant time and money [3]. Otherwise, rural people fall back on local, expensive informal financial service alternatives to manage their finances.

Studies confirmed that a branchless banking system is the most convenient banking platform that helps to assure financial inclusion [4][3]. It is more essential when individuals are excluded from banking services by barriers such as high fees, distance, and lack of suitable services. Additionally, for the banks, it has more cost advantage than a branch-based banking system[5][6]. Thus, most developing countries come up with policies that support the adoption of a branchless banking system. In 2012, the National Bank of Ethiopia also announced a proclamation that allows commercial banks and microfinance institutions to provide mobile and agent banking services as part of inclusive financial services for the unbanked part of the rural community.

The advancement of information technology paves the way for the branchless banking system expansion. It introduced a new dimension to the traditional branch-based banking system where services are delivered using agents, mobile, and internet outlets. These outlets may coexist or be used independently. The agent banking system, especially mobile banking operates based on information technology without location constraints [7]. Relatively, internet banking requires more telecom infrastructure, user's skills, and trust to transact over the internet [2].

Nevertheless, previous studies of BBS adoption that takes agent, mobile, and internet banking into monologues model are hardly available. Most studies focused on an agent or mobile banking outlets [7][2][8][9][10]. However, the present study used an equation that integrates agent, mobile, and internet banking into a monologue BBS adoption model. This model helps to predict the most commendable and outrageous BBS outlet for rural communities.

Nowadays, to study the user's intention of BBS adoption, technology acceptance theories such as TAM (technology acceptance model), IDT (innovation diffusion theory), TTF (task-technology fit), and UTAUT (unified theory of acceptance and usage of technology) were used. Relatively, TAM is the most widely used theory of technology acceptance [11][12][13].

TAM is primarily designed to study IT adoption in the context of an organization where employees' intentions are determined by organizational factors such as availability of support, incentives, and 
personal behavior[14]. Whereas, users of BBS are a society whose intentions are guided through socio-cultural values, trust in new technology, and environmental factors such as availability of local agents, access to mobile and information technology infrastructures. In this regard, TAM has limitations as a model to study the adoption of BBS.

To examine the adoption of BBS as part of inclusive financial services for pastoral communities of Somali regional state, the present study has extended the original technology acceptance model (TAM) by adding sociocultural factors, facilitating conditions, and trust constructs.

Somali regional state (SRS) is the second-largest region in Ethiopia where more than $85 \%$ are pastoral Muslim communities living in the rural part of the country. Currently, there are several new developments of financial services in the region such as the introduction of interest-free banking, mobile, internet, and agent banking. Nevertheless, the services are limited around the main cities. Thereby, most rural territories are unbanked, especially pastoral communities. Accordingly, the primary objective of the study is to examine the determinants of pastoral communities' intention to adopt BBS.

\section{Theory and hypothesis}

\section{Theory of technology acceptance}

In the context of branchless banking adoption behaviors studies,[9]identified technology acceptance theories such as Theory of reasoning action (TRA), technology acceptance model (TAM), innovation diffusion theory (IDT), task-technology fit (TTF), and unified theory of acceptance and usage of technology (UTAUT).

TAM is the most widely used model of IT adoption and use [15][16]. It is primarily designed to study IT adoption in the context of an organization. Theory of reasoning action (TRA) is a theory that drowns from social psychology to predict a wide range of behaviors. In this model, the major constructs that determine intention and behavior are attitude and social norm. Then, a theory of planned behavior (TPB) extended TRA by adding the construct of perceived behavioral control [15]. [16] also extended TRA into the technology acceptance model (TAM). TAM is tailored to information system that designed to predict information technology acceptance and usage on the job. Unlike TRA and TPB, TAM excludes the social norm and added perceive ease of use and perceive usefulness constructs. TAM confirmed that perceive ease of use is the determinate of attitude and perceived usefulness. Additionally, the model noted that PU is the direct determinate of attitude and behavioral intention.

TAM2 extended TAM by removing attitude and including social influence as an additional predictor of intention in the case of mandatory settings. The social influence process comprised the subjective norm, image, and voluntarism while the cognitive instrumental process included job relevance, perceived ease of use, output quality, and result demonstrability. In the aftermath of TAM2, all extensions have excluded the attitude construct. Despite this, TAM3 and UTAUT added facilitating conditions and other moderating variables. 


\section{Research framework}

Despite TAM's popularity, it has some limitations as a model to study the adoption of BBS. Users of $\mathrm{BBs}$ are a society whose actions are guided through sociocultural values. In the context of an organization, employees' action is directed by organizational principles and facilitating conditions. As such, sociocultural factors and environmental factors (facilitating conditions) were not the concern of TAM. Differently, the present study is incorporated SCF and FC as the determinant of BI.

[15][14][16] measured attitude, PU, PEU, and BI directly and independently. As such, most previous TAM extensions did not measure the indirect effect of TAM constructs. For example, in testing for the significance vs. non-significance of the hypothesized relationships, [14] has controlled the effect of one or more other variables. [11] criticized the previous TAM as PU and PE models were developed separately and not much is known about possible crossover effectsthat is, could determinants of perceived usefulness influence perceived ease of use and/or could determinants of perceived ease of use influence perceived usefulness? This study investigating and theorizing about potential crossover effects or ruling out the possibility of these effects is an important step in developing a more comprehensive network around TAM.

The effect of attitude on BI is the most controversial construct of TAM. Attitude is developed from the belief people hold about the object of the attitude [17]. It is a response to a stimulus [18]. TAM posits that attitude is the direct determinant of BI. However,[11] proclaimed that the relationship between attitude and intention to be spurious and resulting from the omission of the other key predictors of performance and effort expectancy. They assumed that the causes for attitude to have a significant effect on BI are the presence of PU and PEOU. To prove this claim, the present study assesses the effect of attitude at the presence and absence of PU and PEOU using effect size (f square) and by adding SCF and FC as the new determinates of BI. Furthermore, in the context of banking services, an individual is more willing to use a system when he/she has trust in the firm and get assurance against financial risks[19]. Accordingly, this study extended the original TAM by adding trust as the direct determinant of the perceived usefulness of BBS.

The other prominent limitation of TAM is model design. All indicators of the measurement model designed as reflexive. However, the nature of the constructs cannot be captured only by reflexive indicators. For example, FC is related to the external environment and personal factors. Since these factors measure different characters, they have to be designed formatively.

Moreover, most of the tests of previous technology acceptance models were conducted well after the participants' acceptance or rejection decision. Exceptionally, [15] measured during the active adoption decision-making process. Differently, this study measures the behavioral intention of an individual before an adoption decision. As such, the study has significant implications for BBS designers. 
Figure 1 Research conceptual framework

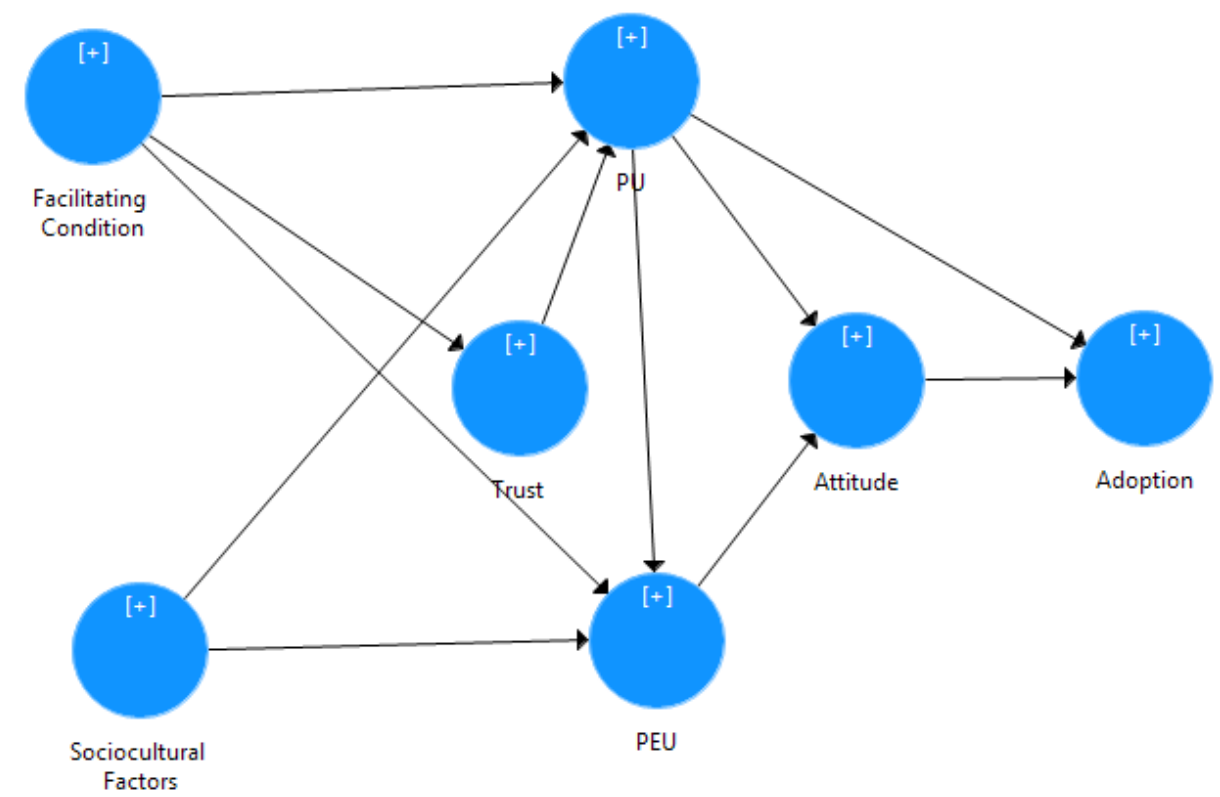

\section{Hypotheses}

\section{Perceived ease of use and related constructs}

In this study, perceived ease of use is operationalized to refer to the degree to which a person believes that using agent, mobile, and internet banking would be free of mental effort. Universally, new technology adoption requires mental efforts. However, regardless of the technology version, the belief on ease of technology has a discrepancy among individuals based on their personal and sociocultural belief and availability of supporting conditions. At the individual level, the person's experience and learning skills determine the level of mental effort required. From the sociocultural perspectives, in most advanced countries and urban areas, technology has a wide acceptance by individuals who are willing to adopt new technologies easily. Nevertheless, in developing countries and rural areas, society may not be willing to adopt new technologies as easily as developed countries. Likewise, in a pro-technology society that promotes the share of knowledge and resource, adoption of new technology is high through perceive ease of use. Regarding facilitating conditions, in areas where telecom infrastructures are high, access for mobile and agent is easy, and supportive government policy exists, the adoption of a branchless banking system is very easy. Accordingly, this study posits that sociocultural factors and access for facilitating conditions determine the individual feeling of mental burden or ease to adopt a branchless banking system. Besides, the original TAM stated that PU directly affect PEU and PEU affect attitude [20]

\section{Hal: SCF directly affect PEU}

Ha2: FC directly affects PEU

Ha3: PU directly affects PEU

Ha4: PEU directly affects attitude 


\section{Ha5: PEU indirectly affects BI through attitude}

\section{Perceived usefulness and related constructs}

Perceived usefulness is defined in this study as the degree to which a person believes that adoption of agent, mobile and internet-banking system would help him or her to get efficient banking service instantly. advancement in technology might not lead to adoption if it is not fulfilling consumers' needs, desires, or perceptions[7].

In a community context, people's interests and perceptions are influenced by SCF and the level of trust in the system. The TTF adoption model suggests that the user will adopt new technology if it is good enough to execute the daily task efficiently [19]. Nonetheless, any useful and efficient system that operates against the socio-cultural values would face serious adoption resistance from individuals. For example, a banking system that receives or pays interest is seriously condemned by the Muslim community. This implies that people tend to follow technological advancements if and only if it is in line with their social values such as religion. As such, the system design should consider SCF as important as PU. In the organizational point of view, [15] also confirmed that subjective influence is significantly affect perceived usefulness in which people use a system to gain status within the workgroup and thereby improve their job performance

Furthermore, before BBS adoption, people may develop negative or positive outlooks (attitude) about the system based on its potential performance (PU). As a result, in TRA and TAM, perceived usefulness is the direct determinant of attitude and behavioral intention to adopt new technology.

Regarding PU and PEU, the perceived usefulness of technology is more important than its perceived ease of use. [16] confirmed that the usefulness-usage relationship remained large, while the ease of use-usage relationship was diminished substantially. This implies, in the long-run PU is more important than PEU.

\section{Hb1: SCF directly affects $P U$}

Hb2: PU directly affect attitude

\section{Hb3: PU directly affects $B I$}

\section{Hb4: PU affects BI through attitude}

\section{Trust and related constructs}

Trust is operationalized as the individual confidence in the existing conditions to perform branchless activities. There is disagreement on the cause and effect relation between trust in the system and belief on performance gain from BBS use. For example, Kim et al., (2009) argued that initial trust in mobile banking would be shaped when the user experiences performance gains from the use of mobile banking. In this case, trust in the system is preceded by belief in performance gain from use. Nevertheless, this study argues that trust in the system is the primary determinant of an individual's belief in performance, especially in banking service. Belief is usually related to 
acceptance of technology as it is valid, but trust is confidence as the reliability, security, and ability of BBS. As such, this study posits that people initially prefer to have confidence in the existing facilitating conditions such as internet transaction security, government support, repeatability of the service providers, etc. of BBS. Then, this initial trust in the supporting conditions can affect his/her belief in the performance of BBS. In support of this notion [19] confirmed that an individual is more willing to trust a new service when there is reputation in the firm and assurance against risks. At large, trust indirectly determine behavioral intention [19]. Accordingly, this study postulates that if an individual lacks trust in the existing facilitating conditions, he will not have a belief in the perceived usefulness of branchless banking services, which leads to low acceptance. In short, facilitating conditions influence trust in BBS; trust in BBS affects belief on the bercieved performance that cascades to a negative or positive attitude on behavioral intention.

\section{Hcl: FC directly affects trust on BBS}

\section{Hc2: Trust in BBS directly affects $P U$}

\section{Hc3: Trust in BBS affects BI through PU}

\section{The indirect effect of sociocultural factors on BI}

Previous studies defined social norm as the degree to which an individual perceives that important others believe he or she should use the new system. In TAM, the social norm was designed as a significant predictor of BI through attitude. Later in TAM 2, the social norm was renamed as social influence. Schepers \& Wetzels, (2007) cited in [21] also confirmed that social influence is partially mediated by the attitude towards technology use. Different from TAM, TAM2 placed social influence as a direct predictor of BI[19].

However, previous technology acceptance theories were focused on social influences in the context of employee acceptance of new technology. This study operationalized social influence as collective socio-cultural values that influence user's acceptance of the branchless banking system. [22] Stated that sociocultural rule makes it possible to analyze the actual circumstances of human action, especially if the concept of habitus is applied to practical understanding and skills that enable a person conform to rules. These rules are usually cascaded through social institutions and individual's social roles such as religious dogma and clan leaders. Culture is defined as principles that are shared across people in a society and these fundamental principles influence individuals' attitudes and behaviors. Van Biljon \& Kotzé, (2008) pointed out that culture greatly affects the acceptance of technology through its belief and values. Thus, culture leads a social influence where members who share the same culture can influence other members within that culture.

In a society like pastoral communities where the daily activities of individuals are interdependent, the impact of sociocultural rules is prominent in an individual's intention to use new technology. In this regard, the sociocultural principle is designed as the primary exogenous construct the influences individual's behavioral intention through the perceived usefulness and performance expectancy of a branchless banking system.

\section{Hd1: SCF affects BI through PU}




\section{Hd2: SCF affects BI through PEU}

\section{The indirect effect of facilitating condition on BI}

In the organizational context, in TAM 2, facilitating condition is defined as the individual's control beliefs regarding the availability of organizational resources and support structure [11]. In this study, the facilitating condition is operationalized to refer to the availability of branchless banking infrastructures to transact over agent, mobile, and internet banking outlets. Nevertheless, the rural population characteristics are not conducive for these services [1]. This study posits that branchless banking adoption will be easy (PUE), useful (PU), and trustworthy if there are sufficient facilitating infrastructures.

He1: FC affects BI through PEU

He2: FC affects BI through trust

He3: FC affects BI through PU

\section{Methodology}

The objective of this study is to predict the factors that determine users' intention to adopt a branchless banking system as part of inclusive financial services for pastoral communities. To achieve this objective, the study used primary data. To collect primary data about the level of agreement on a five-point Likert scale is used: 'Strongly disagree' $(=1)$, 'Disagree' $(=2)$, 'Neither agree nor disagree' $(=3)$, 'Agree' $(=4)$, 'Strongly agree' $(=5)$. The constructs and their respective indicators are listed in table 1.

Table 1 list of constructs and their respective indicators

\begin{tabular}{|l|l|}
\hline SCF & Sociocultural Factors (Independent) \\
\hline SCF1 & My religion influence branchless banking system use \\
\hline SCF2 & $\begin{array}{l}\text { Clan leaders, relatives, and friends may influence my intention to use branchless } \\
\text { banking system use }\end{array}$ \\
\hline SCF3 & $\begin{array}{l}\text { Whenever I get difficulty with branchless banking service use, I can easily get help from } \\
\text { society }\end{array}$ \\
\hline SCF4 & My culture promotes the sharing of mobile \\
\hline SCF5 & In my culture, only men deal with finances \\
\hline FC & Facilitating conditions (Independent) \\
\hline FC1 & Near my area, there are many potential agents speak my language \\
\hline FC2 & Near my area, there are an electric power supply and good internet overages \\
\hline FC3 & Access for mobile is easy for me ( cost) \\
\hline FC4 & Good Government policies and regulations that secure the branchless banking system \\
\hline T & Trust ( Dependent) \\
\hline T1 & I trust agents to perform banking activities \\
\hline T2 & I trust mobile to perform banking activities \\
\hline T3 & I trust internet to perform banking activities \\
\hline
\end{tabular}




\begin{tabular}{|l|l|}
\hline PU & Perceived usefulness ( Dependent) \\
\hline PU1 & Agent banking system is useful and quick to do banking activities \\
\hline PU2 & Mobile banking service is useful and quicker to do banking activities \\
\hline PU3 & Internet banking service is useful and quicker do banking activities \\
\hline PEU & Perceived Ease of Use( Dependent) \\
\hline PEU1 & Agent banking is easy to operate \\
\hline PEU2 & Mobile banking is easy to operate \\
\hline PEU3 & Internet banking is easy to operate \\
\hline A & Attitude ( Dependent) \\
\hline A1 & Using agent banking is a good idea \\
\hline A2 & Using mobile banking is a good idea. \\
\hline A3 & Using internet banking is a good idea \\
\hline BI & Behavioral Intention ( Dependent) \\
\hline BI1 & I intended to use a branchless banking system soon \\
\hline
\end{tabular}

The study employed a partial list square-structural equation model (PLS-SEM) that is usually preferred when the research objective is theory development and explanation of variance or prediction of the constructs. In the PLS-SEM application, regardless of the population, the sample size is determined based on 10 times the maximum number of arrowheads pointing at a latent variable. This study model has a maximum of five number of arrowheads pointing at the sociocultural construct. As such, the sample size of this study would be 50. Based on their accessibility, ten study areas were judgmentally selected. In this regard, the purposive sampling method was applied to select the targeted 50 unbanked pastoral communities.

\section{Regression model}

PLS-SEM categorized constructs into exogenous and endogenous variables. Endogenous constructs are dependent on the values of its neighboring constructs. As shown in table 1, facilitating conditions and sociocultural constructs are exogenous constructs. Whereas, perceived usefulness, perceived ease of use, trust, attitude, and behavioral intention are endogenous or dependent constructs.

Structural model calculations are ran by the partial regressions for the dependent construct. The independent constructs are used to estimate the path coefficients. Hence, there is a partial regression model for the five dependent constructs (trust, PU, PEU, Attitude, and BI) to estimate all the path coefficients in the structural model. Formally, the equations for the five dependent constructs are stated as follows

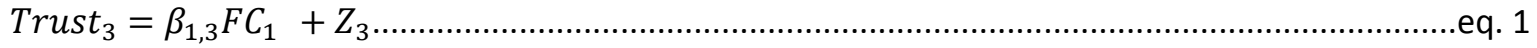

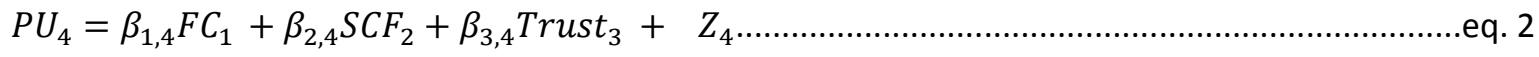

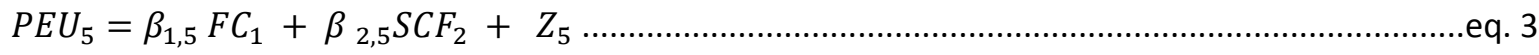

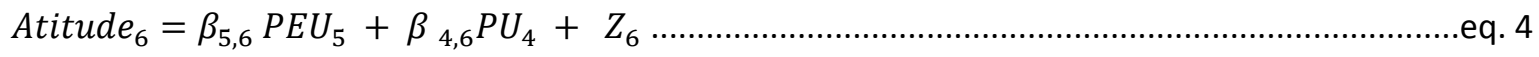




\section{Results}

\section{Measurement model}

Significance and relevance of the outer weight and collinearity testes are employed to evaluate the formative measurement model. A variable inflated factor (VIF) is the primary criterion used to test collinearity. The maximum and minimum thresholds are 5 and 0.2 respectively. As shown in Table 2 , the maximum and minimum VIF are 2.236 and 1.025. As such, collinearity problem is not an issue for the formative measurement model.

To test the significance and relevance of formative indicators, 5000 bootstrap samples were used. Table 2 indicated that among 21 formative indicators' weight, only SCF4 and SCF5 are not significant to predict sociocultural score.

Table 2 Significance and relevance of outer weight and Variable inflated factors

\begin{tabular}{|c|c|c|c|c|c|}
\hline \multirow[t]{2}{*}{ Constructs } & \multirow[t]{2}{*}{ Indicators } & \multicolumn{3}{|c|}{$\begin{array}{l}\text { Significance and Relevancy of } \\
\text { Formative }\end{array}$} & \multirow{2}{*}{ 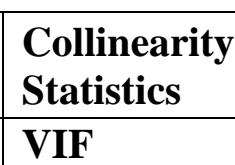 } \\
\hline & & Weight & t-stat & P-value & \\
\hline \multirow{4}{*}{$\begin{array}{l}\text { Facilitating } \\
\text { Condition (FC) }\end{array}$} & FC1 & $0.581^{* *}$ & 4.27 & 0.000 & 1.4 \\
\hline & FC2 & $0.531 * *$ & 3.67 & 0.000 & 1.372 \\
\hline & FC3 & $0.361^{* *}$ & 2.78 & 0.005 & 2.164 \\
\hline & FC4 & $0.327^{* *}$ & 2.88 & 0.004 & 2.236 \\
\hline \multirow{5}{*}{$\begin{array}{l}\text { Sociocultural } \\
\text { Factors (SCF) }\end{array}$} & SCF1 & $0.541^{* *}$ & 4.75 & 0.000 & 1.816 \\
\hline & SCF2 & $0.459^{* *}$ & 5.58 & 0.000 & 1.484 \\
\hline & SCF3 & $0.114^{*}$ & 1.91 & 0.056 & 1.024 \\
\hline & SCF4 & $0.15 \mathrm{NS}$ & 1.63 & 0.103 & 1.816 \\
\hline & SCF5 & $0.06 \mathrm{NS}$ & 0.95 & 0.342 & 1.309 \\
\hline \multirow[t]{3}{*}{ Trust (T) } & $\mathrm{T} 1$ & $0.652 * *$ & 10.18 & 0.000 & 1.321 \\
\hline & $\mathrm{T} 2$ & $0.331^{* *}$ & 4.43 & 0.000 & 1.266 \\
\hline & $\mathrm{T} 3$ & $0.327^{* * *}$ & 5.34 & 0.000 & 1.095 \\
\hline \multirow{3}{*}{$\begin{array}{l}\text { Perceived } \\
\text { Usefulness (PU) }\end{array}$} & PU1 & $0.714 * *$ & 13.32 & 0.000 & 1.799 \\
\hline & PU2 & $0.264^{* * *}$ & 3.83 & 0.000 & 1.469 \\
\hline & PU3 & $0.171^{* *}$ & 2.73 & 0.006 & 1.654 \\
\hline \multirow{3}{*}{$\begin{array}{l}\text { Perceived Ease of } \\
\text { Use (PEU) }\end{array}$} & PEU1 & $0.557^{* *}$ & 4.45 & 0.000 & 1.371 \\
\hline & PEU2 & $0.395^{* *}$ & 2.71 & 0.007 & 1.518 \\
\hline & PEU3 & $0.299 * *$ & 3.17 & 0.002 & 1.293 \\
\hline \multirow{3}{*}{ Attitude (A) } & A1 & $0.78^{* *}$ & 11.85 & 0.000 & 1.434 \\
\hline & A2 & $0.386^{* *}$ & 5.62 & 0.000 & 1.025 \\
\hline & A3 & $0.169^{* *}$ & 2.59 & 0.000 & 1.417 \\
\hline
\end{tabular}




\section{Structural model}

Like the measurement model, the collinearity of each constructs also measured using VIF. The general predictive capacity of the model and the relative contribution of each construct is measured by $\mathrm{R}$ and $\mathrm{f}$ squares respectively. Table 3 presents the VIF of each predictive constructs. The results are within the threshold of 0.2 and 5. Thus, eliminating, merging, or creating higher-order constructs would not be necessary.

Table 3 Collinearity statistics outer model

\begin{tabular}{|l|l|l|l|l|l|}
\hline & PU & PEU & Trust & Attitude & BI \\
\hline Trust (T) & 4.507 & & & & \\
\hline $\begin{array}{l}\text { Sociocultural } \\
\text { Factors (SCF) }\end{array}$ & 3.02 & 3.86 & & & \\
\hline $\begin{array}{l}\text { Facilitating } \\
\text { Condition (FC) }\end{array}$ & 2.144 & 1.69 & 1.00 & & \\
\hline $\begin{array}{l}\text { Perceived } \\
\text { Usefulness (PU) }\end{array}$ & & 4.61 & & 2.800 & 2.366 \\
\hline $\begin{array}{l}\text { Perceived Ease of } \\
\text { Use (PEU) }\end{array}$ & & & & 2.800 & 2.366 \\
\hline Attitude (A) & & & & & 2.366 \\
\hline
\end{tabular}

Coefficients of determination $\left(\mathbf{R}^{2}\right)$ : This coefficient is a measure of the model's predictive accuracy. The predictive accuracy of the stipulated model is 0.676 . This means CF, SCF, trust, PEU, PU, and attitude have explained more than 0.79 of the variance of BI in branchless banking system adoption. 
Figure 2 Initial path model results

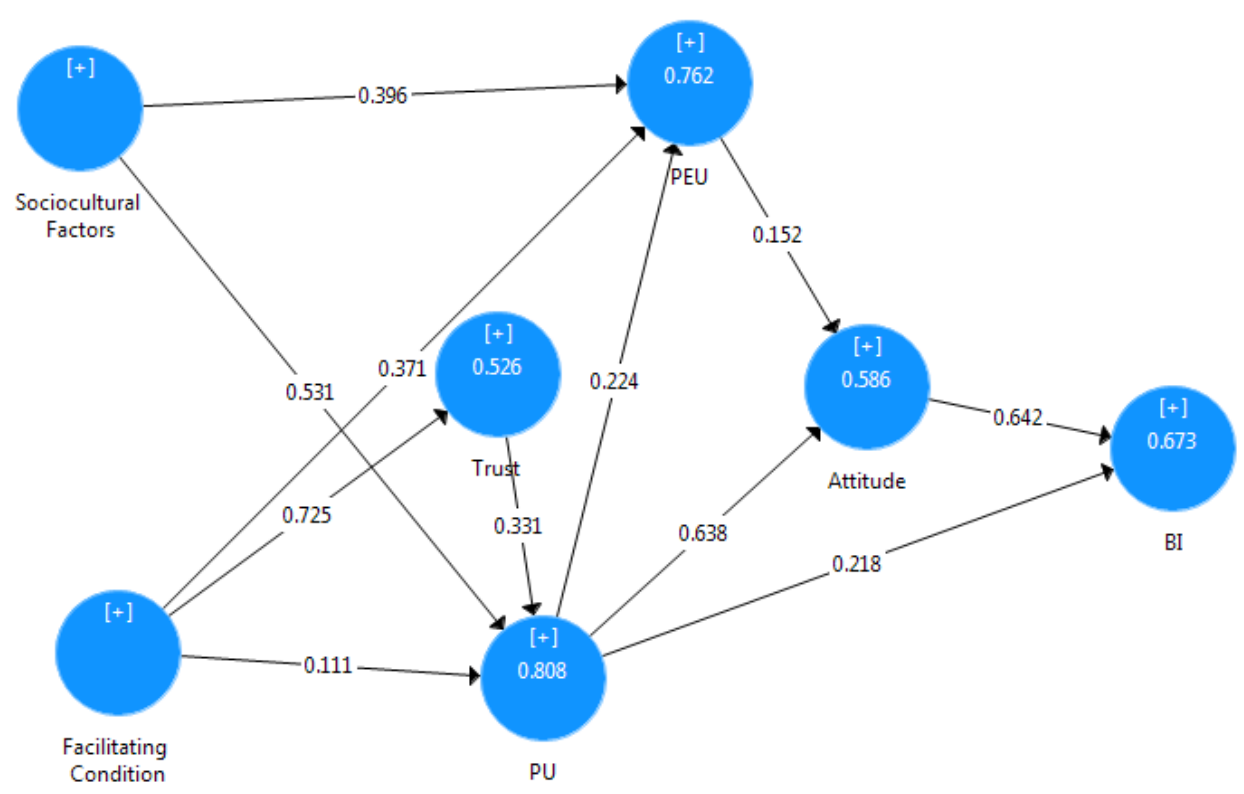

Effect sizes (f square): In the previous section, $\mathrm{R}^{2}$ was used to measure the predictive relevance of the study conceptual framework. But it does not measure the scale and impact of dropping a given subsystem from the model. To do so, the appropriate statistical tool is $\mathrm{f}$ square. It was employed to measures the change in the $\mathrm{R}$ square value when a specified exogenous construct is omitted from the model. This value is used to evaluate whether the omitted construct has a substantive impact on the accounting information users' satisfaction. Guidelines for assessing $\mathrm{f}$ square are that values of $0.02,0.15$, and 0.35 , represent small, medium, and large effects respectively.

Table 4 f square ( $\mathrm{R}$ square)

\begin{tabular}{|l|l|l|l|l|l|}
\hline & PU (0.808) & PEU (0.762) & Trust (0.526) & Attitude (0.586) & BI ( 0.673) \\
\hline Trust (T) & 0.127 & & & & \\
\hline $\begin{array}{l}\text { Sociocultural } \\
\text { Factors (SCF) }\end{array}$ & 0.485 & 0.17 & & & \\
\hline $\begin{array}{l}\text { Facilitating } \\
\text { Condition (FC) }\end{array}$ & 0.03 & 0.34 & 1.11 & & \\
\hline $\begin{array}{l}\text { Perceived } \\
\text { Usefulness (PU) }\end{array}$ & & 0.05 & & 0.351 & 0.062 \\
\hline $\begin{array}{l}\text { Perceived Ease of } \\
\text { Use (PEU) }\end{array}$ & & & & 0.020 & \\
\hline Attitude (A) & & & & & 0.534 \\
\hline
\end{tabular}


Figure 2 The size effect of omitting attitude from the structure model on BI

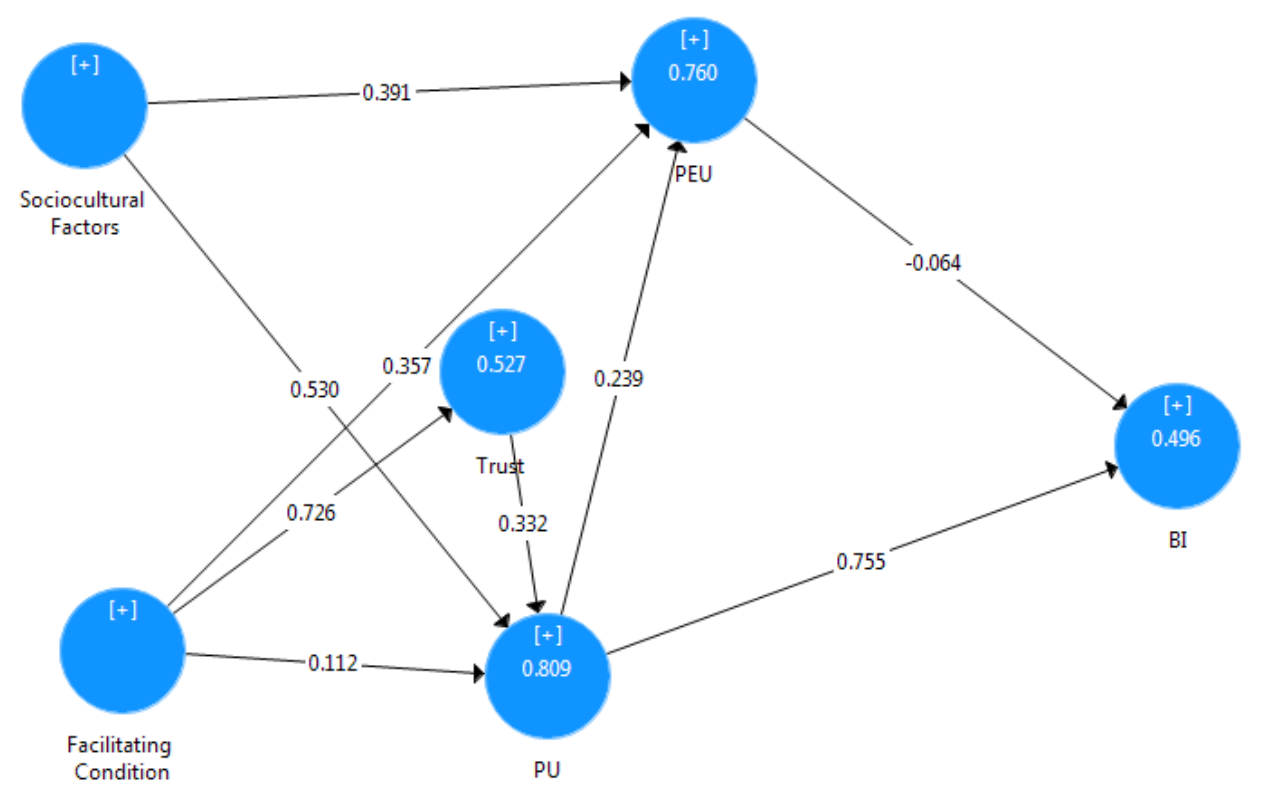

In Table 4, attitude has a larger size effect on BI than PU. As shown in Figure 2, omitting attitude from the model reduced $\mathrm{R}$ square from 0.673 to 0.496 . Regarding attitude's predictive constructs, PU has the largest size effect than PEU. Omitting FC from the model could reduce the R square of PEU more than it would be reduced by SCF and PU omission. Conversely, omitting SCF from the model could reduce PU's R square than it would be reduced by FC and trust exclusions. Collectively, the predicting constructs have met at least the small size effect requirement (0.02). Thus, all constructs are retained in the structure model for further analysis.

\section{Hypotheses testing}

Most previous technology acceptance methods have focused on the direct relationships of constructs in the context of organizations. This study extended previous technology acceptance methods in the context of indirect effect analysis. The following section presents the direct and indirect effects of predicting constructs followed by total effect. The direct effect analysis logically is broken into an extension of TAM (exogenous constructs) and original TAM direct effects

\section{Direct effect}

Facilitating conditions (FC) and socio-cultural factors (SCF) are the exogenous constructs that extended from TAM external variables. The study hypothesizes that facilitating condition has a significant effect on PEU, PU, and trust. The result in Table 5 confirmed these assertions. FC significantly explained an individual's trust $(\beta=0.725 ; P<0.01)$ on branchless banking service followed by perceived ease of the technology $(\beta=0.371 ; P<0.01)$. Nonetheless, the effect of FC on PU is significant when the p-value is 0.1 . The direct effect of SCF on Perceived usefulness (PU) $(\beta=0.531 ; P<0.01)$ and perceived ease of use $(\mathrm{PEU})(\beta=0.396 ; P<0.01)$ are significant. The only endogenous (internal) construct extended from TAM is trust $(\mathrm{T})$. The 
result confirmed that an individual's trust in a branchless banking system significantly explains perceived usefulness $(\beta=0.331 ; P<0.01)$.

Table 5 Direct effect

\begin{tabular}{|l|l|l|l|l|l|l|l|}
\hline \multicolumn{2}{|l|}{ Extension of TAM constructs } & \multicolumn{3}{l|}{ Original TAM direct relations } \\
\hline Relation & $\begin{array}{l}\text { Path } \\
\text { Coefficients }\end{array}$ & t-statistics & p-value & Relation & $\begin{array}{l}\text { Path } \\
\text { Coefficients }\end{array}$ & $\begin{array}{l}\text { t- } \\
\text { statistics }\end{array}$ & $\begin{array}{l}\text { p- } \\
\text { value }\end{array}$ \\
\hline $\mathrm{FC} \rightarrow \mathrm{PEU}$ & $0.371 * * *$ & 5.37 & 0.000 & PEU $\rightarrow \mathrm{A}$ & $0.152 \mathrm{NS}$ & 1.452 & 0.147 \\
\hline $\mathrm{FC} \rightarrow \mathrm{PU}$ & $0.111^{*}$ & 1.745 & 0.077 & PU $\rightarrow \mathrm{A}$ & $0.638 * * *$ & 5.854 & 0.000 \\
\hline $\mathrm{FC} \rightarrow \mathrm{T}$ & $0.725 * * *$ & 21.12 & 0.000 & PU $\rightarrow \mathrm{PEU}$ & $0.224 * *$ & 1.986 & 0.047 \\
\hline $\mathrm{SCF} \rightarrow \mathrm{PEU}$ & $0.396 * * *$ & 4.124 & 0.000 & PU $\rightarrow \mathrm{BI}$ & $0.218 * * *$ & 3.493 & 0.001 \\
\hline $\mathrm{SCF} \rightarrow \mathrm{PU}$ & $0.531 * * *$ & 5.483 & 0.000 & $\mathrm{~A} \rightarrow \mathrm{BI}$ & $0.642 * * *$ & 9.694 & 0.000 \\
\hline $\mathrm{T} \rightarrow \mathrm{PU}$ & $0.331 * * *$ & 2.967 & 0.000 & & & & \\
\hline & & & & & & & \\
\hline
\end{tabular}

$* * * \mathrm{P}<0.01 ; * * \mathrm{p}<0.05 ; * \mathrm{p}<0.1 \mathrm{NS}:$ Non-significance

In the original TAM, there are five direct effects, namely PEU and PU on A, PU on PEU, PU and attitude on BI. The results, also confirmed a significant direct effect of PU on A $(\beta=0.638 ; P<$ $0.01)$, $\mathrm{PU}$ on $\mathrm{PEU}(\beta=0.224 ; P<0.05)$, $\mathrm{PU}$ on $\mathrm{BI}(\beta=0.218 ; P<0.01)$, and $\mathrm{A}$ on $\mathrm{BI}(\beta=$ $0.642 ; P<0.01)$. However, the effect of PEU on attitude is not confirmed $(\beta=0.152 ; P>$ $0.01)$.

\section{Indirect specific effects}

TAM and its extended versions focused only on direct effects. This study addressed both direct and indirect effects. As shown in Table 6, all indirect effects through perceived ease of use are not significant. Additionally, the effect of SC on BI through PU, FC effect on BI through PU and A, FC effect on BI through PU, and PEU effect on BI through attitude are not confirmed. Collectively among 12 indirect effects on BI, six are statistically significant. PU on BI scored the largest indirect effect on $\mathrm{BI}(\beta=0.41 ; P<0.00)$ followed by $\operatorname{SCF}(\beta=0.217 ; P<0.01)$.

Table 6 Indirect effect

\begin{tabular}{|l|l|l|l|l|}
\hline Specific indirect effect & $\begin{array}{l}\text { Path } \\
\text { Coefficient }\end{array}$ & t-statistics & p-values & Decision \\
\hline $\mathrm{SCF} \rightarrow \mathrm{PU} \rightarrow \mathrm{BI}$ & $0.116 \mathrm{NS}$ & 2.69 & 0.007 & Rejected \\
\hline $\mathrm{SCF} \rightarrow \mathrm{PU} \rightarrow \mathrm{A} \rightarrow \mathrm{BI}$ & $0.217 * * *$ & 4.09 & 0.000 & Accepted \\
\hline $\mathrm{SCF} \rightarrow \mathrm{PEU} \rightarrow \mathrm{A} \rightarrow \mathrm{BI}$ & $0.045 \mathrm{NS}$ & 1.55 & 0.122 & Rejected \\
\hline $\mathrm{FC} \rightarrow \mathrm{PEU} \rightarrow \mathrm{A} \rightarrow \mathrm{BI}$ & $0.036 \mathrm{NS}$ & 1.43 & 0.153 & Rejected \\
\hline $\mathrm{FC} \rightarrow \mathrm{PU} \rightarrow \mathrm{A} \rightarrow \mathrm{BI}$ & $0.045 \mathrm{NS}$ & 1.54 & 0.124 & Rejected \\
\hline $\mathrm{FC} \rightarrow \mathrm{T} \rightarrow \mathrm{PU} \rightarrow \mathrm{A} \rightarrow \mathrm{BI}$ & $0.098^{* *}$ & 2.29 & 0.022 & Accepted \\
\hline
\end{tabular}




\begin{tabular}{|l|l|l|l|l|}
\hline $\mathrm{FC} \rightarrow \mathrm{T} \rightarrow \mathrm{PU} \rightarrow \mathrm{BI}$ & $0.053^{* *}$ & 2.78 & 0.023 & Accepted \\
\hline $\mathrm{FC} \rightarrow \mathrm{PU} \rightarrow \mathrm{BI}$ & $0.024 \mathrm{NS}$ & 1.63 & 0.104 & Rejected \\
\hline $\mathrm{T} \rightarrow \mathrm{PU} \rightarrow \mathrm{A} \rightarrow \mathrm{BI}$ & $0.136^{* *}$ & 2.33 & 0.020 & Accepted \\
\hline $\mathrm{T} \rightarrow \mathrm{PU} \rightarrow \mathrm{BI}$ & $0.072^{* *}$ & 2.33 & 0.020 & Accepted \\
\hline $\mathrm{PU} \rightarrow \mathrm{A} \rightarrow \mathrm{BI}$ & $0.41^{* * *}$ & 4.59 & 0.000 & Accepted \\
\hline $\mathrm{PEU} \rightarrow \mathrm{A} \rightarrow \mathrm{BI}$ & $0.098 \mathrm{NS}$ & 1.39 & 0.164 & Rejected \\
\hline
\end{tabular}

\section{Final model results}

As shown in Figure 3, by dropping the non-significant construct (PEU) and adjusting insignificant direct and indirect relations, an extended TAM model for branchless banking system adoption is developed. From the original TAM, perceived ease of use is dropped and new external (FC and SCF) and internal variables (trust) are added. This adjustment enabled the model to explain 67.6 $\%$ of the variation in the BI to adopt a branchless banking system. As shown in Tables 5 and 6 , within the 23 hypotheses formulated, 7 were not confirmed.

Figure 3 Extended TAM model for branchless banking system adoption

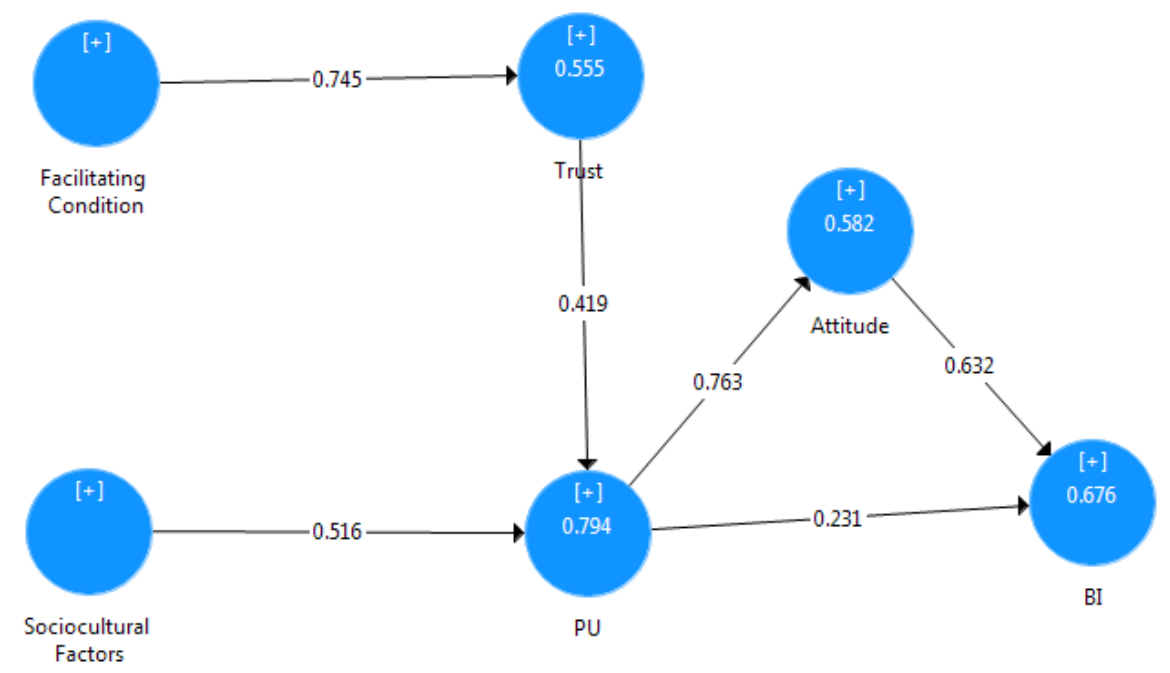

As shown in Table 7, the behavioral intention to adopt a branchless banking system is largely influenced by the perceived usefulness of the system (0.713). Explicitly, the indirect effect (0.482) is more than its direct effect $(0.213)$. The second important direct predictor of $\mathrm{BI}$ is attitude ( $\beta=$ $0.632)$. Regarding indirect effects, SCF $(\beta=0.368), \mathrm{T}(\beta=0.299)$, and $\mathrm{FC}(\beta=0.223)$ are significantly influence $\mathrm{BI}$ at $1 \%$ significance level. The third important predictor of $\mathrm{BI}$ is $\mathrm{SCF}(\beta=$ $0.368)$. Trust on the BBS could influence $\operatorname{BI}(\beta=0.299)$ more than influenced by facilitating conditions $(\beta=0.223)$.

Results in the rows of Table 7 show the relative effect of predicting constructs on the dependent endogenous variables. There by, SCF and trust significantly $(\mathrm{p}<0.01)$ explained BI, A and PU. Specifically, SCF has explained PU more that it could explain BI and attitude. 
Table 7 Final model total effects (direct +indirect)

\begin{tabular}{|l|l|l|l|l|}
\hline & BI & A & PU & T \\
\hline A & 0.632 Dt. & & & \\
\hline PU & $0.713(0.213+0.482)$ & 0.763 Dt. & & \\
\hline SCF & 0.368 It. & 0.394 It. & 0.52 Dt. & \\
\hline T & 0.299 It. & 0.32 It. & 0.42 Dt. & \\
\hline FC & 0.223 Id. & 0.238 It. & 0.31 It. & 0.75 Dt. \\
\hline
\end{tabular}

Note: all effects are significant at $1 \%$. Dt.: Direct effect; It.: Indirect effect

Differently from predicting constructs of the model, FC significantly explained most constructs (BI, A, PU, and T). Relatively, FC explained trust than its indirect effect on BI, A, and PU.

\section{Indicators effect on BI}

Previous studies examined the adoption of agent, mobile, and internet banking systems independently. Differently, this study has examined the adoption of agent, mobile, and internet banking systems altogether as branchless banking channel. It is a comprehensive model consisted of 21 formative indicators. Different from reflexive indicators, each formative indicators of a given construct reveal a distinct character. As such, individual's response for agent, mobile, and internet banking system are different. From each predicting constructs, one important indicator was selected. Table 8 shows the importance-performance map results of the top five indicators that determine behavioral intention to adopt BBS.

Among these indicators, the perceived usefulness of agent banking system has the prominent effect on behavioral intention ( 0.553 ) followed by attitude towards agent banking system (0.5). Religion is the third important indicator of sociocultural construct that affect individuals intention to adopt BBS (0.225). Trust on the agent banking system (0.192) and availability of facilitating condition for agents (0.172) are the fourth and fifth determinants of BI respectively.

Table 8 the importance-performance map results

\begin{tabular}{|l|l|l|}
\hline Constructs & Indicator & Weight \\
\hline Perceived usefulness & Agent BS & 0.553 \\
\hline Attitude & Agent BS & 0.5 \\
\hline Sociocultural Factors & Religion & 0.225 \\
\hline Trust & Agent BS & 0.192 \\
\hline Facilitating Conditions & Local agents availability & 0.172 \\
\hline
\end{tabular}

As stated in Table 9, individual's trust on agent banking system (0.192) is higher than trust on mobile (0.102) and internet (0.099) banking system. Likewise, the perceived usefulness of agent banking system (0.553) is found to be the most important BB outlet followed by mobile banking system (0.132). As a result, the score of attitude towards agent banking system (0.5) overweight the mobile (0.245) and internet (0.1) banking outlets. 
Table 9 Total effect of BBS outlets indicators on BI

\begin{tabular}{|l|l|l|l|}
\hline & Agent & Mobile & Internet \\
\hline Perceived usefulness & 0.553 & 0.132 & 0.119 \\
\hline Attitude & 0.5 & 0.245 & 0.1 \\
\hline Trust & 0.192 & 0.102 & 0.099 \\
\hline
\end{tabular}

\section{Discussion and conclusion}

Most theories of technology adoption focused on the organizational context of employee technology acceptance. However, in the perspective of social acceptance, there is a dearth of theories. Among the organizational related technology acceptance theories, TAM has considered social psychology to predict an individual's intention towards new technology adoption through attitude. Thus, TAM is a suitable theory to model behavioral intention of branchless banking system adoption. The primary limitation of TAM is it overlooked important determinates of BI. As such, TAM's predicting capacity was limited to 40\% [11]. Even though latest theories of technology acceptance (TAM2, UTAM, and TAM3) have included more determinant constructs, they focused more on the organizational perspective by excluding attitude as a spurious construct. In support of this [11][15][23] claimed attitude has a significant effect on BI that resulted from lack of PU and PEU determinants and the PU and PEU effect on attitude.

To test the first claim that the original TAM lacks major determinants of PU and PEU, the present study added three new determinants of PU and PEU. Then, the result confirmed that the effect of attitude on intention is still significant. Moreover, the model has explained more than $67 \%$ of the variance in behavioral intention. This result is more than the variance originally explained by TAM, which was $40 \%$. On the other hand, without attitude, the model has explained only $46 \%$ of the variance in BI. Thereby, this study found that whether more determinants of PU and PEU are loaded or omitted, the effect of attitude on behavioral intention is statistically significant.

Though previous studies argue that attitude has a significant effect on intention due to the PU and PEU effect on attitude, they did not statistically measure the portion of attitude that explained behavioral intention due to the PU and PEU effect. This implies previous studies solely focused on the direct effects. To fill this gap, the present study sought to measure the indirect effect of PU and PEU on behavioral intention through attitude. Here, the result was astonishing. Including the original TAM, previous studies have confirmed that PEU and PU have a significant direct effect on attitude. However, this study found that only PU has a significant direct effect on attitude. Releasing PEU from the model has a small size effect on attitude and the model in general (f square=0.02). Thus, regardless of the PEU effect, attitude has a significant direct effect on behavioral intention ( $\beta=0.642$ ). Literarily, the user's negative or positive feeling is more directed by the importance of technology than its elegance. As a result, the study focused on the role of PU in the context of attitude effect on BI. To measures the change in the r square value of attitude when a PU is omitted from the model, the study employed the f square test. Even though the drooping of PU has a substantial effect (f square of 0.35) on attitude, the result confirmed the significant effect of attitude on BI. Thus, this study asserted that regardless of PU and PEU, attitude is the important construct that predicts behavioral intention to use a branchless banking system. This finding is in contradiction of previous studies who considered any observed association 
between attitude and intention to be false and resulting from the exclusion of the other main predictors. The present study has employed a monologue measurement model that reflected all direction effects of a specific construct with its size impact on the model. This is the possible reason why the finding is different from previous studies that used a separate measurement model, which depicted only direct effects. In support of this study finding, recent studies have also reconfirmed the importance of attitude in social psychology as an indispensable tool for the understanding of behavioral intention [17]. Besides, TRA, TPB, TAM, and motivational model found a significant effect of attitude on BI.

Regarding PU and PEU, [16] proclaimed that the importance of usefulness over ease of use has significant implications for designers, particularly in the human factors tradition who have tended to overemphasize ease of use and overlook usefulness. This study also confirmed that perceived usefulness is an important determinant of BI, but perceived ease of use is not significant.

Overall, the present study has extended the original TAM by adding facilitating conditions and sociocultural factors as external predicting variables and trust as an endogenous constructs.

\section{Facilitating condition}

In previous studies of technology acceptance, the core concept of FC was the availability of organizational support. However, this concept overlaps with perceived ease of use. On the other hand, FC effect on BI is captured by perceived ease. In response to this, [24] stated that the facilitating condition would affect BI if effort expectancy is not existed in the model.

In this study, the facilitating condition is operationalized in the context of environmental factors that simplifies the adoption of a branchless banking system. The availability of local agents, power supply, and the internet, access for mobile, and viable government regulation that secure transactions over branchless banking outlets is environmental factors that explain FC. In this regard, the result indicated that PEU does not capture the concept of FC. The result confirmed that FC directly affects an individual's trust in the technology. Specifically, the existence of local agents with government/ institution guaranty on banking transactions leads users to have trust in the technology. Contrast with [23][15] the study confirmed that FC is significantly determine behavioral intention to adopt a branchless banking system through trust, PU, and attitude.

\section{Sociocultural factors}

Different theories have denoted social influence in different ways. It was represented as a subjective norm in TRA and TAM2, the social norm in TAM, social factors in MPCU, and image in information diffusion theory. Nevertheless, all terms describe the individual's behavior influenced by others view as a result of using a new technology [21]. Even though this study has retained the previous essence of social influence, it incorporated cultural factors such as religion, language, and social role. In this study, the term sociocultural factor is refer the social and cultural factors that influence an individual's decision of branchless banking system adoption. Recent studies confirmed the effect of sociocultural factors in technology adoption [8][25]. 
[15] found that social influence has more effect on perceived usefulness than perceived ease of use. This study also confirmed that the effect of SCF on perceived usefulness is more substantial than its effect on perceived ease. In this regard, users are more sensitive to the alignment of technology usefulness with their sociocultural values. Accordingly, any elegant branchless banking system has no acceptance if it is not designed following the socio-cultural values of users.

In TAM, the social norm was designed as a predictor of BI through attitude. TAM 2 placed social influence (social norm) as a direct determinant BI. Differently, this study found that sociocultural factor is the direct determinant of perceived usefulness. Besides, it affects behavioral intention through attitude and perceived usefulness.

Among the indicators of sociocultural factors, the study found that the impact of religion on behavioral intention is more substantial. The Muslim communities are reluctant to use interestbearing banking services. Thereby, a branchless banking system should be designed in line with the user's religious dogma. Generally, the improvement of technology might not lead to acceptance if it is not contemplated the users' socio-cultural values, specifically religion.

Since most technology acceptance theories focused on organizational context, they overclocked the effect of an individual's trust on technology acceptance. In the context of a branchless banking system, customers' trust is the primary factor to perform banking activities using agent, mobile, and internet systems [4]. In support of this, the result confirmed that trust is the significant determinant of the perceived usefulness of BBS. This is also in line with [26] who state individual's belief on the importance of BBS is more substantial if users are confident on internet security to transact using the internet and mobile. Moreover, the present study found that the availability of local agents and government regulation that secure branchless banking systems significantly affect the user's trust. This implies, facilitating conditions affect trust in branchless banking service that determines the user's perception about its importance.

Several banking studies of technology acceptance examined the adoption of mobile, agent, and internet banking systems independently. Most of them confirmed the effect of initial trust on the user's behavioral intentions. In contrast, this study examined agent, mobile, and internet banking system altogether. The result also supported the significant effect of trust on behavioral intention through perceived usefulness and attitude. To identify the most trusted and useful branchless banking outlet, the study compared the total effect of each outlet on behavioral intention. Accordingly, the agent banking system is found to be the most trusted and useful branchless banking outlet followed by the mobile banking system.

\section{References}

[1] R. Rachmawati, N. M. Farda, and B. Setiyono, "Model of agents-based branchless banking services development in urban and rural area," Indones. J. Geogr., vol. 52, no. 1, pp. 69-79, 2020, doi: 10.22146/ijg.48452.

[2] M. A. Zaffar, R. L. Kumar, and K. Zhao, "Using agent-based modelling to investigate diffusion of mobilebased branchless banking services in a developing country," Decis. Support Syst., vol. 117, no. October 2018, pp. 62-74, 2019, doi: 10.1016/j.dss.2018.10.015.

[3] T. Yuliaty, "Study Of Branchless Banking Business Model," no. January, 2018, doi: 10.2991/ebic-17.2018.72.

[4] A. A. Chaudhry, A. Parveiz, and Y. Javed, "Determinants of users trust for branchless banking in Pakistan," J. Internet Bank. Commer., vol. 21, no. 1, p. 80847, 2016. 
[5] S. Chopra and A. M. Sherry, "Enhancing Branchless Banking Technology Solutions for Improving Consumer Adoption,” Since J. Bus. Manag., pp. 2011-2015, 2015, doi: 10.7237/sjbm/297.

[6] R. Mahmood, E. B. Limited, and S. Sarker, "Inclusive Growth through Branchless Banking: A Review of Agent Banking and its Impact Inclusive Growth through Branchless Banking: A Review of Agent Banking and its Impact," no. June, 2016.

[7] S. K. Abbas, H. A. Hassan, J. Asif, B. Ahmed, F. Hassan, and S. S. Haider, "Integration of TTF, UTAUT, and ITM for mobile Banking Adoption," Int. J. Adv. Eng. Manag. Sci., vol. 4, no. 5, pp. 375-379, 2018, doi: 10.22161/ijaems.4.5.6.

[8] J. van Biljon and P. Kotzé, "Cultural factors in a mobile phone adoption and usage model," J. Univers. Comput. Sci., vol. 14, no. 16, pp. 2650-2679, 2008, doi: 10.3217/jucs-014-16-2650.

[9] M. K. Gharaibeh, M. R. M. Arshad, and N. K. Gharaibh, "Using the UTAUT2 model to determine factors affecting adoption of mobile banking services: A qualitative approach," Int. J. Interact. Mob. Technol., vol. 12, no. 4, pp. 123-134, 2018, doi: 10.3991/ijim.v12i4.8525.

[10] Z. Ahmed, A. Kader, B. U. Harun Rashid, and B. Mohammad Nurunnabi, "User Perception Of Mobile Banking Adoption: An Integrated Ttf-Utaut Model,” J. Internet Bank. Commer., vol. 22, no. 3, 2017, doi: Journal of Internet Banking and Commerce.

[11] V. Venkatesh and H. Bala, "Technology Acceptance Model 3 and a Research Agenda on Interventions Subject Areas: Design Characteristics, Interventions," Decis. Sci., vol. 39, no. 2, pp. 273-315, 2008, [Online]. Available: http://www.vvenkatesh.com/wp-content/uploads/2015/11/Venkatesh_Bala_DS_2008.pdf.

[12] P. C. Lai, "The Literature Review Of Technology Adoption Models And Theories For The Novelty Technology," vol. 14, no. 1, pp. 21-38, 2017, doi: 10.4301/S1807-17752017000100002.

[13] T. Sciences, "A Study On The Acceptance Of Information Technologies From The Perspectives Of The Academicians In," vol. 10, no. 3, pp. 791-812, 2010.

[14] J. Fred D. Davis, "A Technology Acceptance Model For Empirically Testing New End-User Information Systems: Theory And Results," 1985.

[15] H. van der Heijden, "U Ser a Cceptance of H Edonic," MIS Q., vol. 28, no. 4, pp. 695-704, 2004.

[16] F. D. Davis and F. Davis, "Perceived Usefulness, Perceived Ease of Use, and User Acceptance of Information Technology," no. January 2015, 1989, doi: 10.2307/249008.

[17] I. Ajzen, "Attitude theory and the attitude-behavior relation .," no. January 1993, 2014.

[18] T. K. Altmann, "Attitude: a concept analysis.," Nursing forum, vol. 43, no. 3. pp. 144-150, 2008, doi: 10.1111/j.1744-6198.2008.00106.x.

[19] T. Oliveira, M. Faria, and M. A. Thomas, "Extending the understanding of mobile banking adoption: When UTAUT meets TTF and ITM International Journal of Information Management Extending the understanding of mobile banking adoption: When UTAUT meets TTF and ITM," no. January 2019, 2014, doi: 10.1016/j.ijinfomgt.2014.06.004.

[20] D. F. D., "DavisBagozzi.pdf," Manage. Sci., vol. 35, no. 8, 1989.

[21] A. Chang, "UTAUT AND UTAUT 2: A Review And Agenda For Future Research," J. Winer., vol. 13, no. 9, pp. 106-114, 2012.

[22] A. Manterys, "Cultural Practices and Social Relations Cultural Practices and Social Relations," no. October, 2018.

[23] V. Venkatesh, J. Y. L. Thong, B. Statistics, X. Xu, and T. Acceptance, "Unified Theory of Acceptance and Use of Technology: A Synthesis and the Road Ahead," vol. 17, no. 5, pp. 328-376, 2016.

[24] J. P. Galan, M. Giraud, and L. Meyer-Waarden, "A Theoretical extension of the technology acceptance model to explain the adoption and the usage of new digital services," 29èmeCongrès Int. IAssociation Française Mark. Rochelle, vol. 33, no. 0, pp. 1-22, 2013, [Online]. Available: https://www.afmmarketing.org/en/system/files/publications/20160429234015_S05_P3_GALAN_GIRAUD_et_MEYER_W AARDEN.pdf.

[25] L. William, "Influencing factors to mobile phone adoption among urban youth in Botswana," J. Media Commun. Stud., vol. 8, no. 1, pp. 8-14, 2016, doi: 10.5897/jmcs2015.0474.

[26] C. Setiyono, M. R. Shihab, and F. Azzahro, "The role of initial trust on intention to use branchless banking application: Case study of jenius," in Journal of Physics: Conference Series, 2019, vol. 1193, no. 1, doi: 10.1088/1742-6596/1193/1/012022. 